\title{
OPERATIONAL MATRIX OF DERIVATIVE FOR JACOBI WAVELETS AND APPLICATION FOR SOLVING SECOND ORDER DIFFERENTIAL EQUTIONS
}

\author{
bahri mohammed nadjib ${ }^{1}$, abbassa nadira ${ }^{2}$, and bahri sidimohamed ${ }^{3}$ \\ ${ }^{1}$ univercity of Mostaganem \\ ${ }^{2}$ University of Abdelhamid Ibn Badis of Mostaganem Faculty of Exact and Computer \\ Sciences \\ ${ }^{3}$ Université Abdelhamid Ibn Badis de Mostaganem Faculté des Sciences Exactes et de \\ l'Informatique
}

January 30, 2022

\begin{abstract}
In this paper, we present a new operational matrix of derivative of Jacobi wavelets. Shifted Jacobi polynomials and their properties are employed for deriving a procedure to forme this matrix. Then Jacobi wavelets expansions along with this operational matrix are applied for solving ordinary differentiel equations with non analytic solution. It is shown that Jacobi wavelets are very efficient and suitable for solving this kind of problem. Several numerical examples are given to illustrate the efficiency and performane of the presented method.
\end{abstract}

\section{Hosted file}

aricl1 (1).pdf available at https://authorea.com/users/458084/articles/554671-operationalmatrix-of-derivative-for-jacobi-wavelets-and-application-for-solving-second-orderdifferential-equtions

\section{Hosted file}

aricl1 (1).tex available at https://authorea.com/users/458084/articles/554671-operationalmatrix-of-derivative-for-jacobi-wavelets-and-application-for-solving-second-orderdifferential-equtions 